https://helda.helsinki.fi

\title{
Microstructure analysis method for evaluating degenerated intervertebral disc tissue
}

\section{Friedmann, Andrea}

2017-01

Friedmann , A , Goehre , F , Ludtka , C , Mendel , T , Meisel , H-J , Heilmann , A \& Schwan , S 2017 , ' Microstructure analysis method for evaluating degenerated intervertebral disc tissue ' , Micron , vol. 92 , pp. 51-62 . https://doi.org/10.1016/j.micron.2016.10.002

http://hdl.handle.net/10138/231344

https://doi.org/10.1016/j.micron.2016.10.002

publishedVersion

Downloaded from Helda, University of Helsinki institutional repository.

This is an electronic reprint of the original article.

This reprint may differ from the original in pagination and typographic detail.

Please cite the original version. 


\title{
Microstructure analysis method for evaluating degenerated intervertebral disc tissue
}

\author{
Andrea Friedmann ${ }^{\mathrm{a}, 1}$, Felix Goehre ${ }^{\mathrm{d}, \mathrm{e}, 1}$, Christopher Ludtka $^{\mathrm{a}, \mathrm{b}}$, Thomas Mendel ${ }^{\mathrm{c}}$, \\ Hans-Joerg Meisel ${ }^{\mathrm{d}}$, Andreas Heilmann ${ }^{\mathrm{a}}$, Stefan Schwan ${ }^{\mathrm{a}, *}$ \\ a Fraunhofer Institute for Microstructure of Materials and Systems IMWS, Department of Biological and Macromolecular Materials, Halle, Germany \\ ${ }^{\mathrm{b}}$ University of Tennessee, Department of Chemical \& Biomolecular Engineering, Knoxville, USA \\ c Friedrich Schiller University, Universitätsklinikum Jena, Department of Trauma Surgery, Jena, Germany \\ d BG Klinikum Bergmannstrost Halle gGmbH, Department of Neurosurgery, Halle, Germany \\ e University of Helsinki and Helsinki University Hospital, Department of Neurosurgery, Finland
}

\section{A R T I C L E I N F O}

\section{Article history:}

Received 23 August 2016

Received in revised form 14 October 2016

Accepted 14 October 2016

Available online 21 October 2016

\section{Keywords:}

Microstructure

Disc tissue

IDD

Delamination

Cell density

Scanning electron microscopy

SEM

\begin{abstract}
A B S T R A C T
Degeneration of intervertebral disc (IVD) tissue is characterized by several structural changes that result in variations in disc physiology and loss of biomechanical function. The complex process of degeneration exhibits highly intercorrelated biomechanical, biochemical, and cellular interactions. There is currently some understanding of the cellular changes in degenerated intervertebral disc tissue, but microstructural changes and deterioration of the tissue matrix has previously been rarely explored. In this work, sequestered IVD tissue was successfully characterized using histology, light microscopy, and scanning electron microscopy (SEM) to quantitatively evaluate parameters of interest for intervertebral disc degeneration (IDD) such as delamination of the collagenous matrix, cell density, cell size, and extra cellular matrix (ECM) thickness. Additional qualitative parameters investigated included matrix fibration and irregularity, neovascularization of the IVD, granular inclusions in the matrix, and cell cluster formation.

The results of this study corroborated several previously published findings, including those positively correlating female gender and IVD cell density, age and cell size, and female gender and ECM thickness. Additionally, an array of quantitative and qualitative investigations of IVD degeneration could be successfully evaluated using the given methodology, resin-embedded SEM in particular. SEM is especially practical for studying micromorphological changes in tissue, as other microscopy methods can cause artificial tissue damage due to the preparation method.

Investigation of the microstructural changes occurring in degenerated tissue provides a greater understanding of the complex process of disc degeneration as a whole. Developing a more complete picture of the degenerative changes taking place in the intervertebral disc is crucial for the advancement and application of regenerative therapies based on the pathology of intervertebral disc degeneration.
\end{abstract}

(c) 2016 Elsevier Ltd. All rights reserved.

\section{Introduction}

Intervertebral disc degeneration (IDD) is a natural process associated with microstructural changes in intervertebral disc (IVD) tissue and is dependent on age and mechanical load, as well as genetic and biochemical factors that act on structural, cellular, and molecular parameters (Antoniou et al., 1996; Singh et al., 2009;

\footnotetext{
* Corresponding author at: Fraunhofer Institute for Microstructure of Materials and Systems IMWS, Walter-Huelse Str. 1, 06120 Halle (Saale), Germany.

E-mail address: Stefan.Schwan@imws.fraunhofer.de (S. Schwan).

1 Andrea Friedmann and Felix Goehre are co-first authors and have contributed equally to this work.
}

Woods et al., 2010; Siemionow et al., 2011; Vergroesen et al., 2015). Disc anatomical changes play a major role in this process, especially the distinction between the fibrillary structure of annulus fibrosus (AF) tissue and the amorphous, hydrous nucleus pulposus (NP) tissue. Interactions between contributing factors result in the complex incidence of IDD, beginning in a patient's teenage years (Buckwalter, 1995; Adams and Roughley, 2006; Colombier et al., 2014) with a decreased concentration of water-retentive proteoglycans in the NP. Morphological impacts from tissue dehydration may include increased tissue fibration and gap generation in the collagenous matrix (Raj, 2008), which further promote the occurrence of disc herniation as the worst-case scenario. From a clinical viewpoint, the incidence of IDD and disc herniation are not always interrelated (Postacchini and Cinotti, 1999). Additional initiating 
events appear necessary for disc herniation of degenerated tissue. There are many possible culprits such as biochemical, histologic, metabolic and functional changes, all of which occur in the disc during the procession of IDD (Urban and Roberts, 1995; Adams and Roughley, 2006; Shankar et al., 2009). Examples of these changes are alterations in the extracellular matrix (ECM) such as increased lamellar disorganization, formation of fibrous tissue, and the production of structural matrix molecules such as elastin and collagen type I, III, VI, and X (Urban et al., 2000; Roberts et al., 2006a,b; Smith and Fazzalari, 2009; Kepler et al., 2013). Changes in stability are often attributed to altered collagen crosslinking (Duance et al., 1998). Structural changes also occur in the disc, resulting in the development of matrix features such as fissures, cracks, and interlamellar gaps (Adams and Roughley, 2006). The exact contribution to IDD of each of these interwoven factors is currently unknown.

In the case of disc herniation there is a definite structural matrix failure that is associated with the discharge of IDD tissue into the spinal canal and the formation of a sequester. For investigation of the structural changes in this sequester tissue, classical histological preparation (Hadjipavlou et al., 2008) is the only suitable method. This is especially true for evaluating which tissue changes are attributable purely to mechanical failure. Therefore, the aim of this work is to present a method of preparation that enables evaluation of cell density, cell distribution, and matrix proportion as well as providing evidenced conclusions about the delamination and tearing processes. Delamination, which is traditionally a material science term for layer separation in compound materials, is defined herein as laminar loosening and cleft formation within the lamellar structure of the degenerated disc tissue (Carlson et al., 2012). This structural change in disc tissue may be one of the previously mentioned initiators required for herniation of degenerated tissue, resulting in mass displacement within the intervertebral disc.

All degeneration characteristics of intervertebral disc tissue are closely related to one another, making a detailed description of IDD increasingly difficult. In order to better understand and describe the incidence of IDD, three age groups were investigated morphologically to study the roles and correlations between delamination and variations in cell density during IDD. Morphological investigations are generally performed using light microscopy by default. High resolution scanning electron microscopy proves to be a promising method for investigating structural properties (Friedmann et al., 2012) as well as micro-morphological details in the tissue, so as to gain deeper insight into tissue structure.

\section{Material and methods}

\subsection{Intervertebral disc tissues excision and patient recruitment}

IVD tissue from 60 disc herniation patients was analyzed regarding degenerative microstructural characteristics to evaluate the pathology of degeneration. All tissue samples were obtained during standard micro-sequestrectomy no more than $72 \mathrm{~h}$ after first onset of herniation symptoms (e.g. paralysis, paresthesia). In each case, the largest fully-intact portion of the sequestrum was collected for future analysis. Patients were grouped into 3 categories by age (21-40, 41-60 and 61-80 years old), then further subdivided by gender. Power analysis was used to determine a sample size ( $n=10$ per age group) from a total population of 1150 lumbar micro-sequestrectomy procedures with a near equal distribution of patient sex. After obtaining informed consent, patients were recruited at random until the group sample size was reached. Removed tissue samples were blinded for all further investigations. Disc identity was verified (e.g. 'L4/L5') and disc degeneration was classified in terms of the 5-grade Pfirrmann Score (PS) (Pfirrmann et al., 2001) by an independent radiologist based on magnetic res- onance imaging (MRI). Exclusion criteria were patients with more than one herniated disc or those with any affecting secondary conditions.

\subsection{Tissue preparation and microscopy}

A minimum volume of approximately $1 \mathrm{~cm}^{3}$ of sequestered disc tissue is required for morphological investigations. Immediately after excision, samples were rinsed liberally in phosphate buffered saline solution (PBS, c.c. pro GmbH Oberdorla, Germany) to remove residual bodily fluids. Samples were then fixed in $2.5 \%$ glutaraldehyde in PBS (GDA, Carl Roth GmbH \& Co. KG, Karlsruhe, Germany) for a minimum of $24 \mathrm{~h}$. Following fixation, samples were again rinsed in PBS and, if sufficient tissue was present, divided into two portions so as to provide tissue for both preparation methods. Sample preparation for light microscopy used paraffin wax embedding while SEM analysis entailed "Spurr" resin embedding.

\subsubsection{Histology and light microscopy}

In preparation for paraffin wax embedding, tissue samples were dehydrated in a series of ethanol solutions of increasing concentration $(10 \%, 30 \%, 50 \%, 70 \%, 90 \%, 100 \%$ and $100 \%$ waterfree ethanol, Carl Roth GmbH \& Co. KG, Karlsruhe, Germany) with a 24 h soak time for each step. Afterwards samples were plasticized using Roti ${ }^{\circledR}$-Histol (Carl Roth GmbH \& Co. KG, Karlsruhe, Germany). Tissue samples then underwent a two-step infiltration with melted paraffin wax (Carl Roth GmbH \& Co. KG, Karlsruhe, Germany) before being transferred to paraffin-filled embedding molds and cooled to $4{ }^{\circ} \mathrm{C}$. For histological staining, $5 \mu \mathrm{m}$ thick sample slices were prepared by a rotation microtome (HM 355, MICROM International GmbH, Walldorf, Germany) and fixed to microscope slides. Prior to staining, samples were dewaxed using Roti $^{\circledR}$-Histol and rehydrated in a reverse stepwise series of ethanol solutions. The staining procedure was performed according to "Masson-Goldner" (Mulisch and Welsch, 2010). General staining provided visualization of collagenous connective tissue, which appears green, while and cell nuclei which appear as black-brown. In addition, the cytoplasm is stained brick red and erythrocytes are coloured bright orange. Histologically prepared samples were then analyzed using light microscopy (BX61, Olympus Europe Group, Hamburg, Germany).

\subsubsection{Resin embedding and scanning electron microscopy}

For SEM investigations tissue samples were stained with $1 \%$ osmium tetroxide (Carl Roth GmbH \& Co. KG, Karlsruhe, Germany) in PBS over a five day period. Samples were then rinsed cleaned of residual osmium tetroxide with 3 PBS washes before stepwise dehydration in acetone $(10 \%, 30 \%, 50 \%, 70 \%, 90 \%, 100 \%$ and $100 \%$ waterfree acetone, Carl Roth GmbH \& Co. KG, Karlsruhe, Germany). The dehydrated samples were then embedded in "Spurr" resin (Sigma Aldrich Chemie GmbH, Taufkirchen, Germany) according to the manufacturer's protocol. The tissue-resin blocks were abraded and polished using a MERCAPOL P230 grinder (Presi Company Grenoble, France) to provide a smooth cross section. Each block's polished surface was then sputter coated (VEB Hochvakuum, Type RHVm42, Dresden Germany) with a 2-3 nm thick layer of platinum to provide the necessary conductive properties for SEM.

Sample blocks were analyzed using a FEI Quanta 3D field emission gun (FEG) scanning electron microscope (SEM) under high vacuum using a back-scattered-electron (BSE) detector to visualize differences in material contrast. SEM not only provides high magnification cell imaging, but also enables detailed microstructural analysis of the tissue matrix. For quantitative analysis of matrix delamination and cell density, 5 regions of interest per specimen were investigated at low magnification $(200 \times)$. Within each of these regions at least 10 bisected IVD cells with a visible cell 


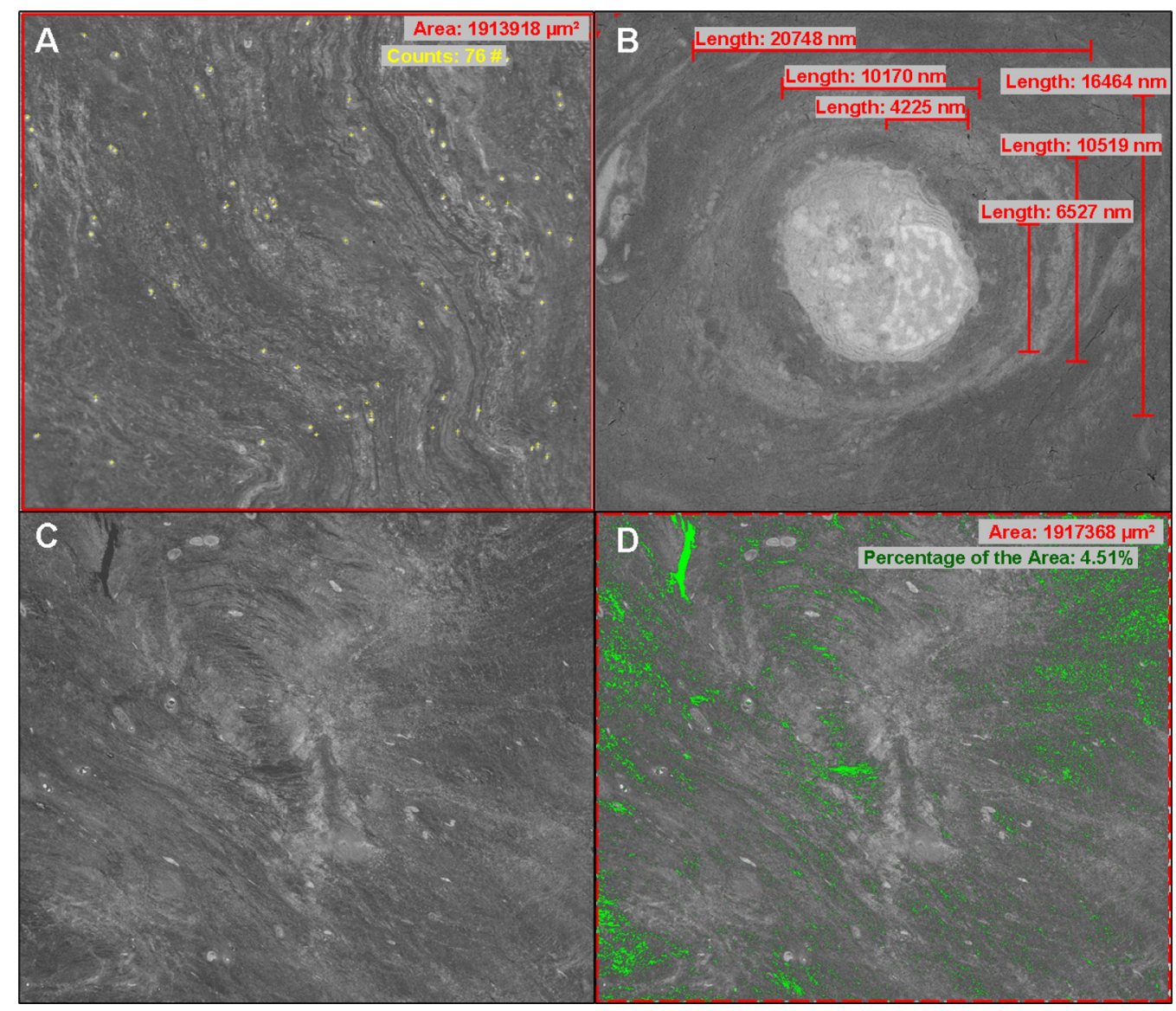

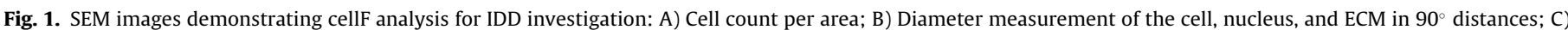

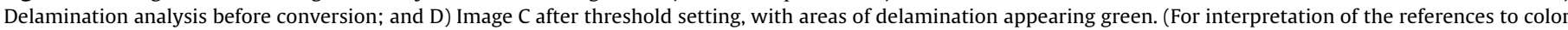
in this figure legend, the reader is referred to the web version of this article.)

membrane, nuclear membrane and ECM were investigated at high magnification (500-1000×) to quantify cell size and ECM capsule thickness. SEM investigations were made with an acceleration voltage of $10-15 \mathrm{keV}$, beam current of $43 \mathrm{pA}$, and a work distance of approximately $5 \mathrm{~mm}$.

\subsection{Image analysis}

The commercially available scientific imaging program Cell ${ }^{\mathrm{F}}$ (Olympus Soft Imaging Solutions GmbH, Münster, Germany) was used for image analysis. Four tissue characteristics were analyzed: cell density, cell size, ECM thickness and tissue matrix delamination. Cell density was measured as average cell count per area across all regions of interest for each individual sample. Cell diameter and ECM thickness were made by distance line measurements for a pre-determined number of cells in each region of interest. In determining cell cross-sectional area, an elliptical cell shape was assumed. In image analysis, delamination is defined as the ratio between the delaminated and non-delaminated surface areas of the sample. To determine delaminated area, images were first converted into $8 \mathrm{Bit}$ format before manually setting the threshold to differentiate compact tissue matrix from delaminated areas (resinfilled with resin material contrast). Example measurements are displayed in Fig. 1: determination of cell density in Fig. 1A, cell morphological parameters cell size and ECM-thickness in Fig. 1B, and measurement of matrix delamination within the disc tissue in Fig. 1C and D (before and after threshold setting, respectively). Additionally, all calculation formulas used to compile results are summarized in Table 1.
The mean value of each parameter was determined from the 5 (cell density, delamination) or 10 (cell morphology) tissue areas analyzed. Significance was determined using one-way analysis of variance (ANOVA) with a 95\% confidence interval (significance level $\mathrm{p}<0.05$ ) to identify any intercorrelations.

\section{Results}

\subsection{Quantitative microstructural analysis}

SEM microstructural analysis of the disc tissue matrix included cell density, matrix delamination, cell size and ECM thickness measurements for all patient samples. Each parameter exhibited a normal distribution. Total values, as well as tissue specific parameters as functions of patients' age and gender, are described in the following subsections. Analysis of variance (ANOVA) was used to determine significant differences in the age and gender groups.

\subsubsection{Cell density}

The total, gender-differentiated, and sex-differentiated cell density distributions are displayed in Table 2 along with the corresponding ANOVA p-values. The interquartile range of the cell density data is $23.86-35.79 \mathrm{c} / \mu \mathrm{m}^{2}$. Female patients generally show slightly higher cell densities than male patients and cell density appears to have a negative trend with patient age. However, neither of these relationships was statistically significant in our dataset.

To evaluate the homogeneity of cell distribution in the tissue samples, 3D cell density counts were conducted in six samples. 3D density was accomplished by preparing and analyzing additional 
Table 1

Calculation formulas for determining tissue specific parameters.

\begin{tabular}{|c|c|c|c|}
\hline & Formula & Parameter & Description \\
\hline $\begin{array}{l}\text { Cell density } \\
\mathrm{d}_{\mathrm{c}}\left[\text { cells } / \mathrm{mm}^{2}\right]\end{array}$ & $d_{c}=\frac{n_{c}}{a}$ & $\begin{array}{l}\mathrm{n}_{\mathrm{c}}-\text { number of cells }[\text { cells] } \\
\mathrm{a}-\text { area }\left[\mathrm{mm}^{2}\right]\end{array}$ & Number of cells per tissue area. \\
\hline $\begin{array}{l}\text { Delamination } \\
\mathrm{D}[\%]\end{array}$ & $D=\frac{a_{d}}{a} \cdot 100 \%$ & $\begin{array}{l}\mathrm{a}_{\mathrm{d}}-\text { area of delamination }\left[\mathrm{mm}^{2}\right] \\
\mathrm{a} \text { - area }\left[\mathrm{mm}^{2}\right]\end{array}$ & Ratio of delaminated and non-delaminated tissue area structure. \\
\hline $\begin{array}{l}\text { Cell size } \\
\mathrm{s}_{\mathrm{c}}\left[\mu \mathrm{m}^{2}\right]\end{array}$ & $s_{c}=\frac{\pi}{4} \cdot h \cdot b$ & $\begin{array}{l}\mathrm{h}-\text { length of cell minor axis }[\mu \mathrm{m}] \\
\mathrm{b}-\text { length of cell major axis }[\mu \mathrm{m}]\end{array}$ & Size of cell cross section under elliptical cell shape assumption. \\
\hline $\begin{array}{l}\text { ECM thickness } \\
l_{\mathrm{ECM}}[\mu \mathrm{m}]\end{array}$ & $l_{E C M}=\frac{\left(b_{E C M}-b\right)+\left(h_{E C M}-h\right)}{4}$ & $\begin{array}{l}h_{E C M}-\text { length of ECM minor axis } \\
{[\mu \mathrm{m}]} \\
h-\text { length of cell minor axis }[\mu \mathrm{m}] \\
b_{E C M}-\text { length of ECM major axis } \\
{[\mu \mathrm{m}]} \\
b-\text { length of cell major axis }[\mu \mathrm{m}]\end{array}$ & Deviation of the cell length and ECM length \\
\hline
\end{tabular}

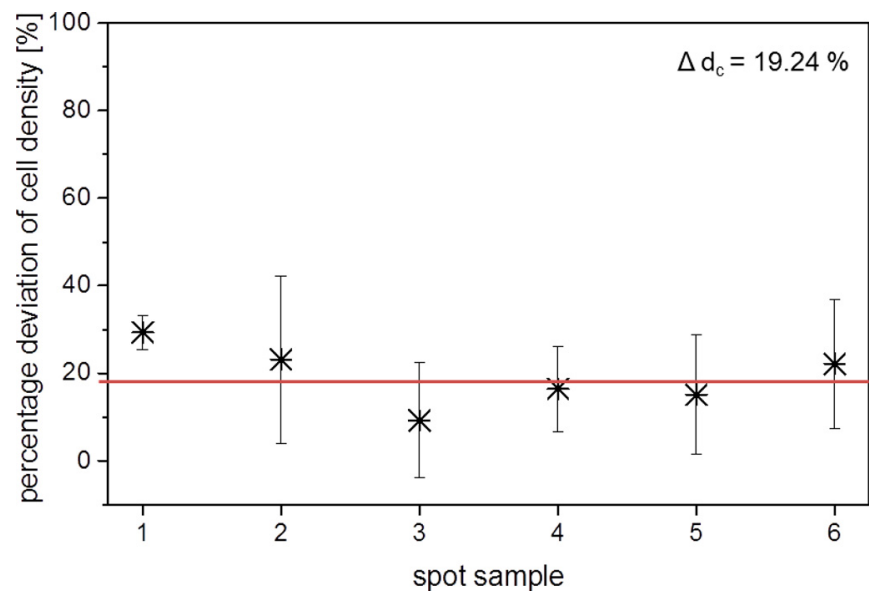

Fig. 2. Mean value and standard deviation of percent deviation for cell densities determined from orthogonal cross sections of 6 samples.

sample block slices parallel to the original slice. The percent deviations of measured cell density for each of the six samples are shown in Fig. 2; the mean deviation is $19.24 \%$.

\subsubsection{Matrix delamination}

Table 3 displays the dataset for matrix delamination in degenerated IVD tissue, including delamination evaluated as a function of patient sex and age with the corresponding means, standard deviations, and p-values also shown. The interquartile range of the total dataset falls between $3.31 \%$ and 5.65\%. Male patients generally exhibited slightly higher delamination than female, but not to a statistically significant degree. Although IDD and the accompanying tissue structural changes have previously been established as an age dependent process, no statistically significant correlation to age was seen in this data set.

\subsubsection{Cell morphology}

Cell size and ECM capsule thickness were measured in crosssection to investigate cell morphology within degenerated IVD tissue. Cell size data is displayed in Table 4 in regard to the total dataset and the dependence on patient gender and age. The interquartile range of the total dataset for cell size, represented by the cross-sectional area, is $74.2-108.1 \mu \mathrm{m}^{2}$. Slightly lower mean values were seen in male patients than in female, though ANOVA shows no significant differences between gender groups. There was however a highly significant positive correlation between IVD cell size and age.

Analysis of ECM thickness showed no correlation to age, as seen in Table 5 (right). Patient sex however showed a correlation, as the ECM capsules of disc cells in female patients were significantly thicker than in male patients (Table 5 , middle). The overall mean value of ECM thickness across all patients is $4.71 \mu \mathrm{m}$ with an interquartile range of 4.11-6.09 $\mu \mathrm{m}$.

\subsection{Qualitative microstructural analysis}

\subsubsection{Granular inclusions}

Intervertebral disc degeneration is characterized by several structural changes within the disc tissue, including calcification of the tissue matrix. Calcified areas are easily detectable via SEM due to higher material contrast and appear as bright granular inclusions within the matrix (Fig. 3).55\% of the overall investigated tissue samples showed granular inclusions and $80 \%$ of the $61-80 \mathrm{yr}$ age group samples had inclusions. $45 \%$ of the $41-60 \mathrm{yr}$ samples and $40 \%$ of the 21-40 yr samples were also affected.

\subsubsection{Neovascularization}

As a result of disc degeneration, neovascularization occurs at the borders of herniated disc tissue. Blood vessel formation is detectable by staining erythrocytes during standard histology. Neovascularization is also detectable by SEM investigation of resin embedded tissue due to the higher material contrast of erythrocytes and their characteristic cell shape (Fig. 4). Investigations of 60 degenerated disc tissue samples showed neovascularization in $58.3 \%$. Furthermore, a noticeably higher incidence of neovascularization was detected in tissues of older patients $(75 \%, 61-80 \mathrm{yr})$ compared to the younger groups (55\% 41-60 yr; 45\%, 21-40 yr).

\subsubsection{Cell cluster formation}

The presence of cell cluster formation was also investigated during this study as a pathological cellular change in degenerated disc tissue. Cell clusters result from concentrated cell proliferation, forming clones of 3 or more cells (Fig. 5E) with a frequency and size that correlate with the progression of degenerative disc disease. These features can be examined both histologically by light microscopy (Fig. 5A and B) and by SEM via resin embedding (Fig. 5C-E). 31.6\% of the investigated samples exhibited pairwise cell formations, known as chondrones (Fig. 5D). Cell cluster formation was detected in 55\% of samples (Fig. 5D). In the remaining $13.3 \%$ of samples, only single cells (Fig. 5C) where visible during investigation. The highest frequency of chondrones was found in the 21-40 yr group (50\%) while the highest frequency of cell clusters was found in the 61-80 yr group (75\%).

There is a slight positive correlation in regard to chondrones and cell clusters. A moderately linear relationship $(r=0.35)$ was seen, but the data did not correlated with any significance $(p=0.19)$.

\subsection{MRI-graded disc degeneration grade}

The MRI-based Pfirrmann score (PS) of each affected disc was also determined, thereby providing a connection to a common clas- 
Table 2

Mean values and standard deviations of cell density: total data (left), correlation to patient sex (middle) and age (right) with corresponding p-values.

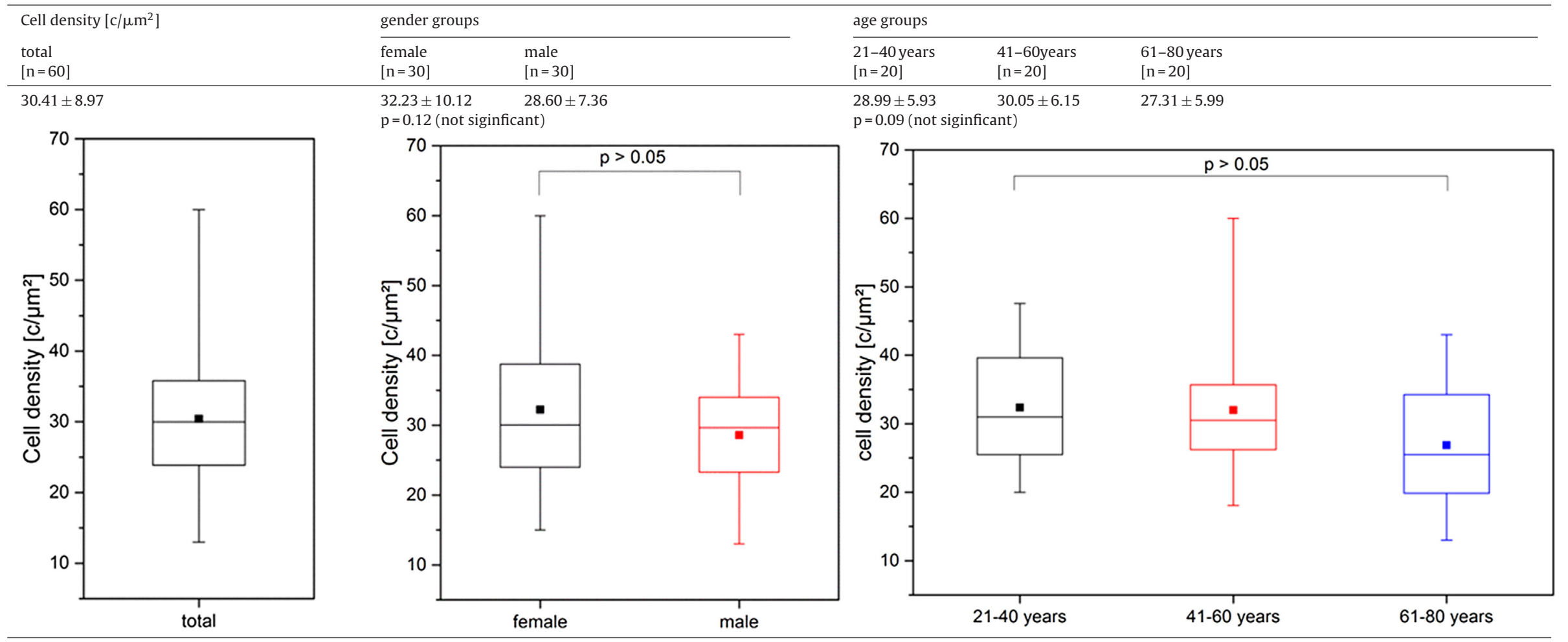


Table 3

Mean values and standard deviations of matrix delamination analysis: total data (left), correlation to patient sex (middle) and age (right) with corresponding p-values.

Matrix gender groups age groups

delamination

[\%]

total

total
$[60]$

$4.50 \pm 1.98$

female

$[\mathrm{n}=30]$

male

$21-40$ years

$[\mathrm{n}=20]$

41-60 years

$61-80$ years

$4.09 \pm 1.93$

$[\mathrm{n}=30]$

$4.90 \pm 1.97$

$\begin{array}{ll}3.97 \pm 1.70 & 4.83 \pm 1.81\end{array}$

$[\mathrm{n}=20]$
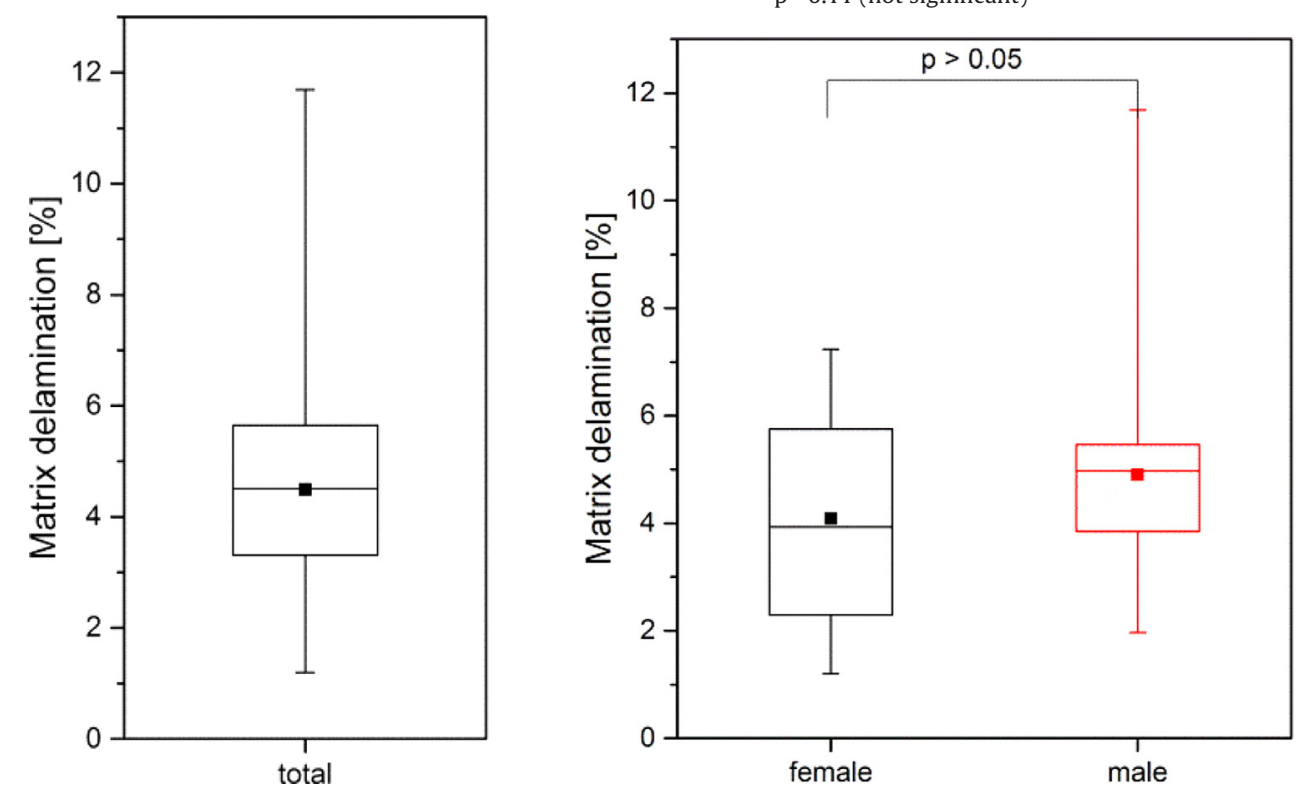

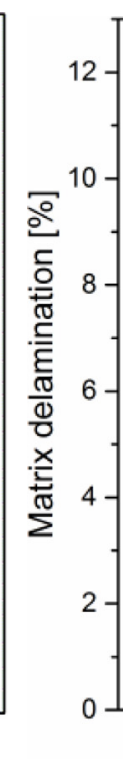

$\mathrm{p}=0.34$ (not siginficant)

$4.69 \pm 2.36$

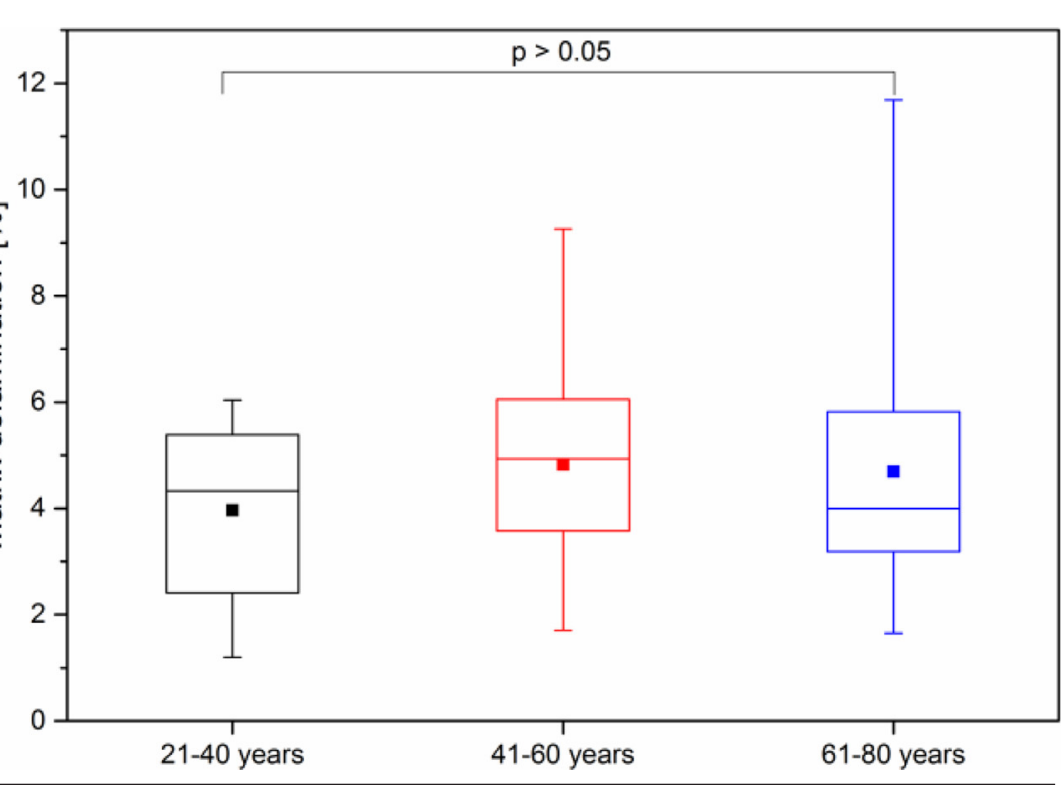


Table 4

Mean values and standard deviations of analyzed cell size: total data (left), correlation to patient sex (middle) and age (right) with corresponding p-values.

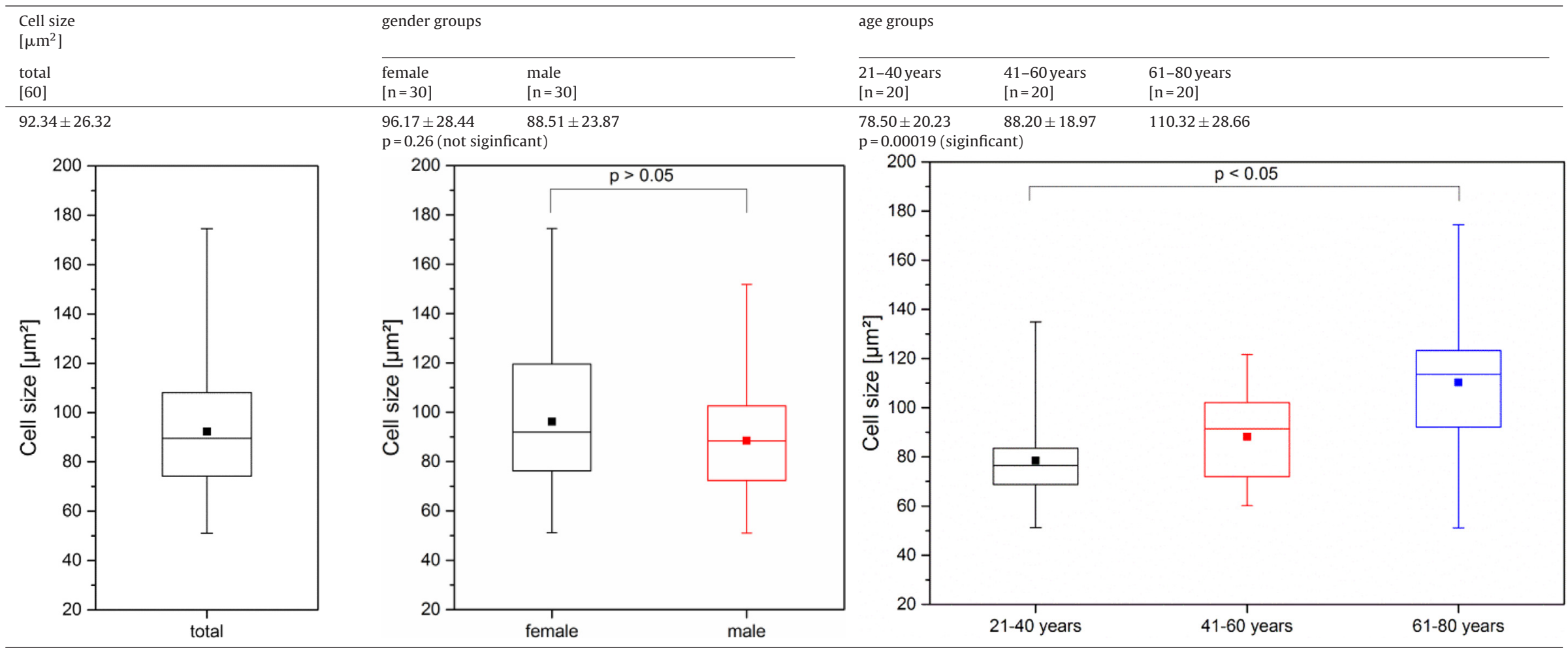


Table 5

Mean values and standard deviations of ECM thickness analysis: total data (left), correlation to patient sex (middle) and age (right) with corresponding p-values.

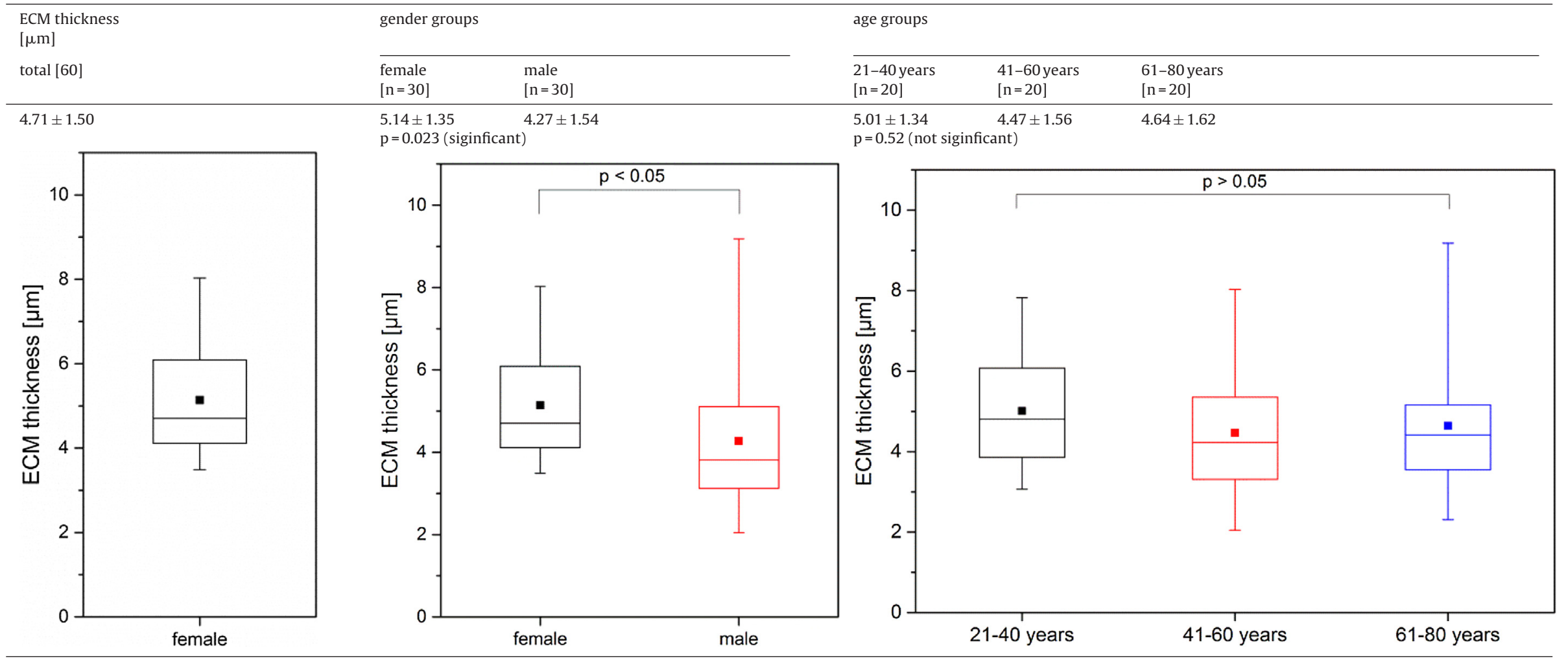



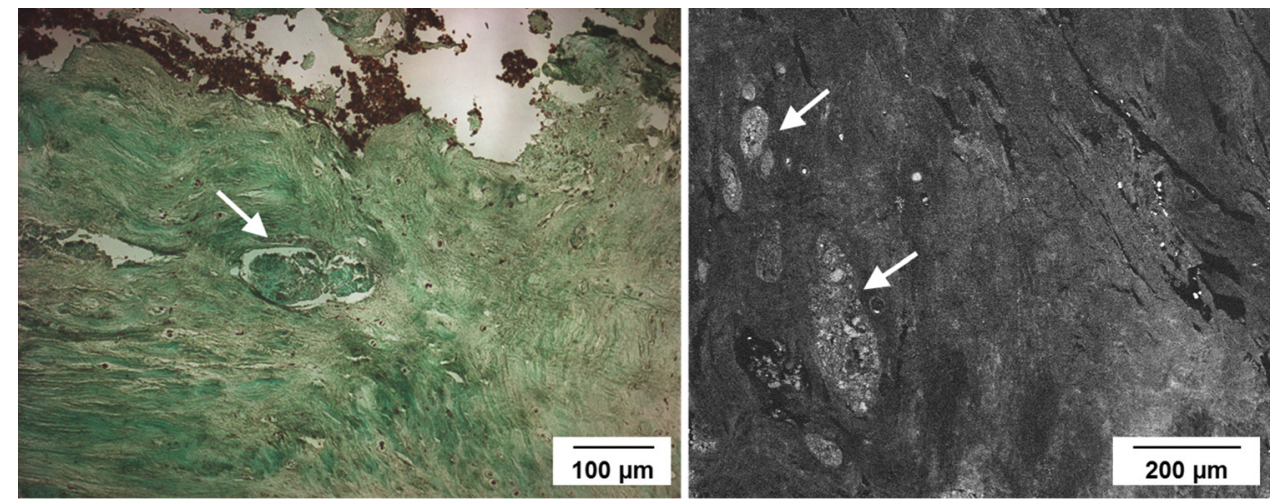

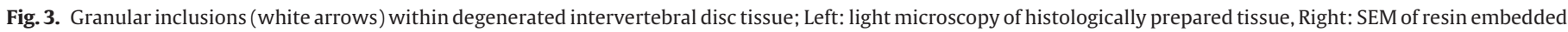
tissue.
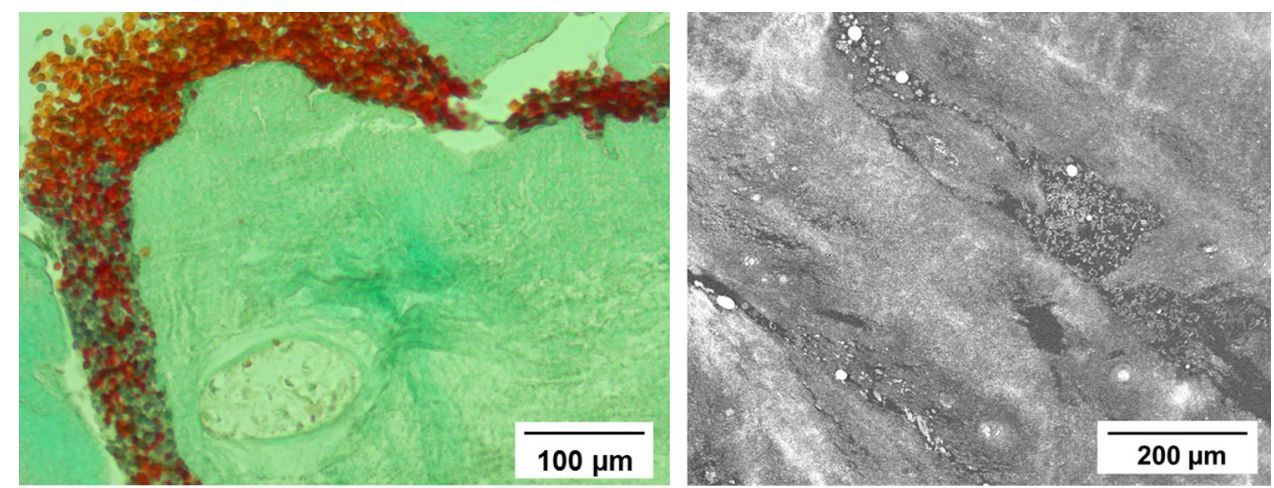

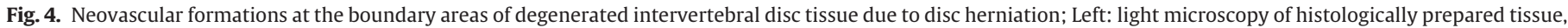
Right: SEM of resin embedded tissue.
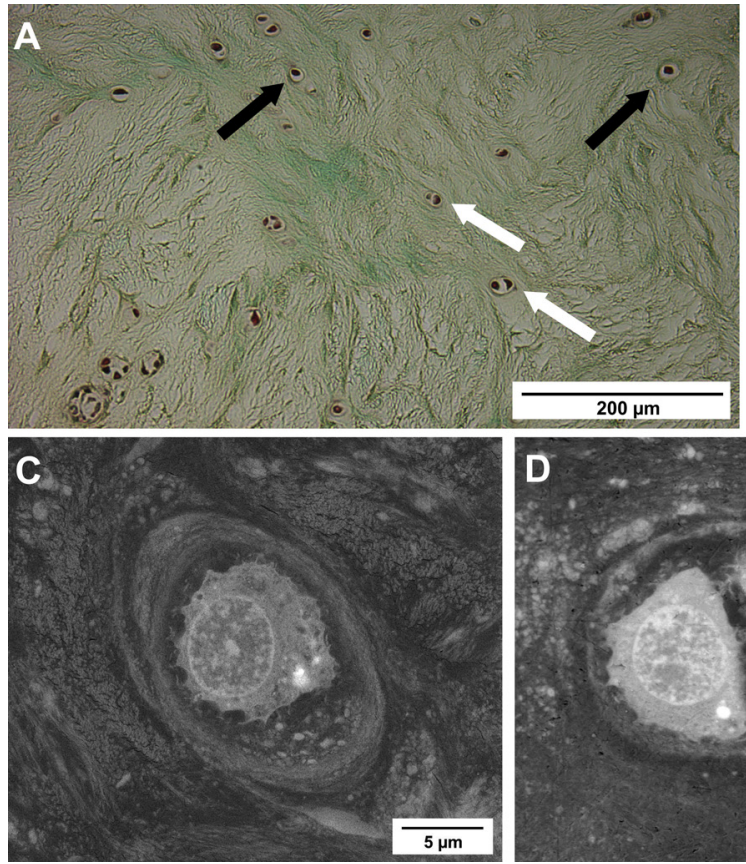
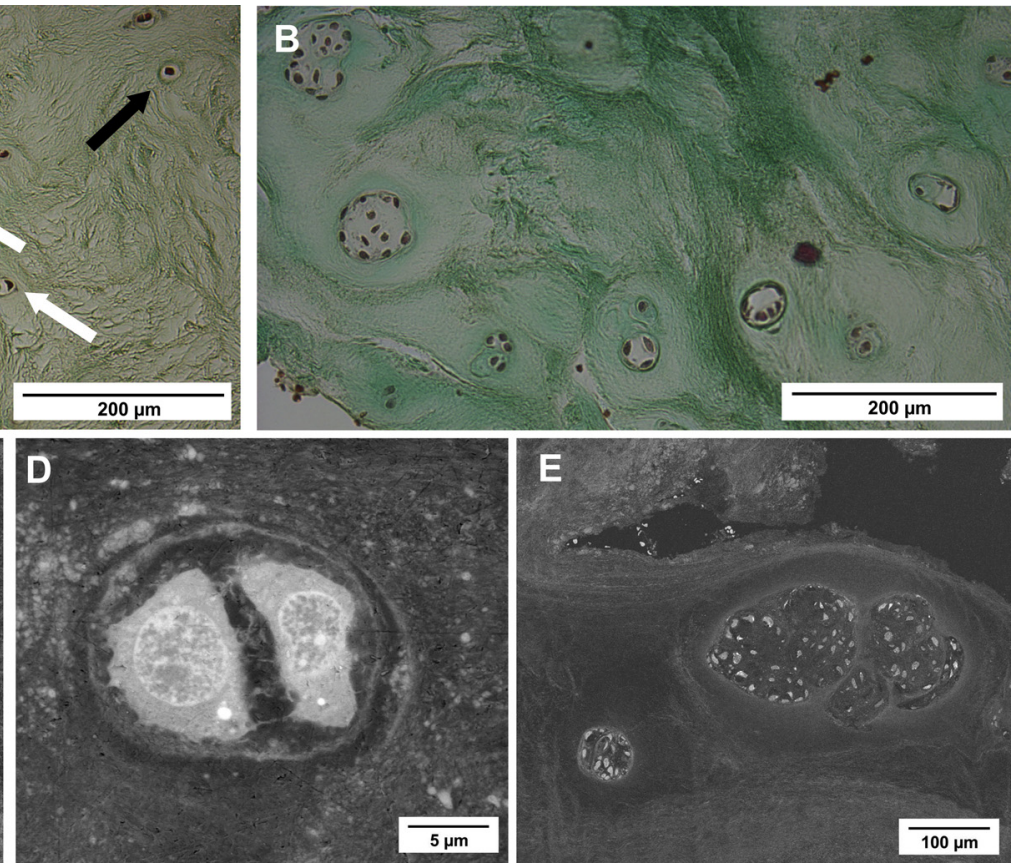

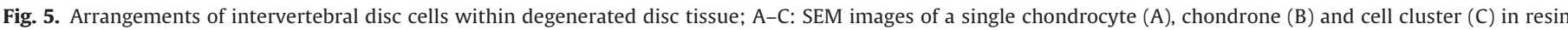

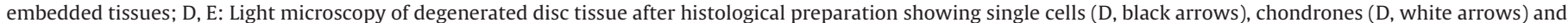
cell cluster formations (E).

sification model used in clinical practice. It is self-evident that all patients were suffering from high grade IDD, considering that treatment via sequestrectomy was necessary. The entire patient set displayed a PS grade of IV or V, thus no direct or meaningful relationship of PS grade to age, gender, cell diameter, cell density, or delamination could be established. 


\section{Discussion}

Considering that all patients in this study suffered from a herniated disc with previous degradation, degenerative changes in the intervertebral disc tissue were to be expected. As described in radiological studies, progressive degeneration leads to an increasingly blurred transition between the AF and NP where a clear distinction between these tissues is no longer possible (Pfirrmann et al., 2001).

As IDD progresses, structural alterations in the disc tissue lead to increasingly blurred boundaries between NP and AF tissue (Urban et al., 2000; Roberts et al., 2006a,b; Kepler et al., 2013) and a loss of distinction between these structures (Pfirrmann et al., 2001). This change corresponds to the macro-morphological fibrous appearance of the investigated specimen. In this study, IDD is classified according to Pfirrmann scores as assessed through preoperative MRI, with every patient receiving a grade IV or V. Matrix delamination of degenerated disc tissue was also evaluated. Due to disorganization of the lamellar structure, delamination is less uniform but nevertheless is an important characteristic of disc degeneration at both the macroscopic and microscopic scale. Further studies should microstructurally evaluate less degenerated disc tissue (Pfirrmann grade I up to III) for comparison and correlation. However, acquiring sequesters from patients with healthy discs has both practical and ethical difficulties and was a limitation in our study.

Approximately $60 \%$ of the surveyed sequestrums showed a markedly irregular fibrous structure. A clear mapping of AF and NP was not possible due to the nature of the tissue. In the literature, structural changes such as AF fiber structure irregularity, NP fibration, and increased formation of collagen I, III, VI, X and elastin are reported characteristics of intervertebral disc degeneration (Urban et al., 2000; Roberts et al., 2006b; Smith and Fazzalari, 2009; Kepler et al., 2013).

Cell density was the first tissue-specific feature evaluated to investigate the pathology of disc degeneration. In the sample group, female patients demonstrated higher cell densities on average, which is consistent with previous findings (Tomaszewski et al., 2015).

Additionally, average disc tissue cell density decreased with increasing patient age, though the difference was not statistically significant. Changes in cell density with regard to the degenerative process have previously been reported, but their specific findings are not consistent and attribute the difference to various factors such as enhanced cell proliferation, local increase in apoptotic reactions, and increased cell death (Trout et al., 1982; Johnson et al., 2001; Gruber et al., 2007; Zhao et al., 2007).

As the IVD consists of avascular cartilage and has comparatively few cells which are firmly locked into the collagen matrix, apoptotic cells are not dismantled or removed from the tissue for extended periods of time. As such they remain in the tissue, which suggests an increase in the disc cell density and cell proliferation over the years. However, this is not the same as an increase in viable cells (Zhao et al., 2007). Therefore, it cannot be freely assumed that cell density in relation to age and degenerative disc disease are truly representative. Scanning electron microscopy studies of disc tissue cell density have the advantage of enabling qualitative evaluation of the cells in terms of vitality thanks to the high resolution. An intact cell and nuclear membrane is vital and is one such characterization of the cell. Such an assessment is not possible in conventional histological examinations. The lower cell density in regard to viable cells that is seen in this study are corroborated by previous reportings that describe a cellular loss during degenerative disc disease (Gruber et al., 2007; Ding et al., 2013). The average deviation of the determined cell density in our study is $19.24 \%$. As no heterogeneous cell distribution was conspicuous in the investigations made, this deviation can be viewed as natural variability of cell density and cell distribution among biological samples. Due to the small sample volume relative to the entire disc, the results of the cell density measurements apply first and foremost to the tissue sequestrums but also pertain to the entire disc.

In addition to structural changes in the tissue matrix, tissue degeneration results from structural damage, such as from overexertion and exercise, which is accompanied by inter lamellar columns and cracks (Adams and Roughley, 2006; Vernon-Roberts et al., 2007). A conventional histological and light microscopy investigation of such tissue damage can be severely flawed, as the microtome and subsequent fixation of the thin sections on slides can cause artificial cracks in the tissue fabric which can be misinterpreted as delamination. Therefore, electron microscopy is a much more suitable method for evaluating matrix delamination as it not only provides high resolution imaging, but also minimizes the likelihood of damage resulting from sample preparation. The percentage of delaminated area was determined for all samples. With increasing age, the water content in the disc and thus its elasticity decreases (Yerramalli et al., 2007; Vergroesen et al., 2015) and the matrix is more susceptible to cracking, particularly under high pressure. Thus, an increase in tissue delamination with increasing patient age is not surprising, although in this study was not a statistically significant correlation. Additionally, delamination values, which reached up to $12 \%$ of tissue area, did not show a significant correlation with the gender of the patient.

SEM allows investigation of chondrocyte morphology at $10,000 \times$ magnification. Most cells exhibited an oval shape, as previously described for cells in the NP or AF (Whatley and Wen, 2012). Patient age demonstrated a significant positive correlation to IVD cell size. This correlation with age is corroborated by findings by Ciapetti et al. (Ciapetti et al., 2012). However, there was no demonstrable correlation between cell size and gender.

In addition to investigation of cell size, electron microscope image analysis also enables a quantitative evaluation of the extracellular matrix directly surrounding the cell. The ECM is described in the literature as a layered cell cavity or cell capsule, with rich ECM being characterized by glycosaminoglycans (Gruber and Hanley, 1998; Ford et al., 2002; Ciapetti et al., 2012). Average thickness of the ECM capsule was calculated by the difference of the orthogonally measured cell and capsule diameter, as seen in Table 2. As the ECM, produced by the IVD cells, constitutes roughly $99 \%$ of the IVD tissue (Roberts et al., 2006b), the balance between matrix synthesis and degradation is of great importance. One aspect of disc degeneration is the loss of this balance. On the one hand, the reinforced matrix degradation occurs due to biochemical changes in the tissue, which in turn are based on errors in the mass transfer in the tissue; on the other, matrix synthesis by IVD cells is reduced (Gruber et al., 2007), which is also attributable to an impaired nutrient supply to the cells. Another cause of reduced matrix production in IVD tissue in the literature is cell aging (Zhao et al., 2007). Senescent cells are vital, but with reduced metabolic activity and are no longer able to proliferate. With increasing age and higher degrees of degeneration, there is an increased occurrence of these aged cells, which are accompanied by reduced matrix production and increased synthesis of other, matrix-depleting enzymes (Roberts et al., 2006a; Gruber et al., 2007; Le Maitre et al., 2007). A significant correlation with age could not be established in this study. However, a significant difference between the sexes was demonstrated, with female patient IVD cells having significantly thicker ECM capsules than those of male patients (Majeed et al., 2016).

Granular inclusions are defined as the accumulation of matrix degradation products and non-collagenous proteins in the tissue (Buckwalter, 1995). Reasons for this granulation include agerelated changes in the biosynthesis of the IVD cells and slow molecular diffusion through the tissue matrix (Colombier et al., 2014). It was observed in this study that the occurrence of these 
deposits in IVD tissue increased with patient age. However, the composition of the deposits has not yet been clearly identified. It has been previously shown that this deposition can be observed via the incorporation of calcium phosphate as well as from increasing calcification of the disc tissue (Hristova et al., 2011). A quick elemental analysis of the investigated samples can be achieved by dispersive X-ray spectroscopy (EDX) (Lee et al., 2006) using an appropriate detector. Such investigations were performed on all samples, but did not provide definitive results regarding pronounced calcification correlated with age. The primary reason for this ambiguity is, among other things, the superposition of numerous elements.

Signs of neovascularization are especially observed in sequestered disc tissue and indicate the body's decomposition reactions (Pai et al., 1999; Kobayashi et al., 2009). It has been previously suggested that the degree of small blood vessel formation in the marginal regions of the sequestered disc tissue may provide information on the age of the disc sequestrum relative to the herniation, i.e. the duration between herniation and surgical excision. Since patients were enrolled in this study with acute, non-relapsed herniated discs and no data on pre-existing conditions was collected, this particular relationship was not examined.

Cell cluster formation is a known feature of degeneration from reports of increased proliferation of single cells or cell clusters in degenerated ECM (Johnson et al., 2001). Another such feature in herniated disc tissue is advanced cell age (Roberts et al., 2006a). The tissue samples analyzed in this study all come from sequestered disc tissue, so degenerative changes in the microstructure were to be expected.

Degenerative changes and even damage to the tissue matrix resulting from stress-related reactions result in increased cell cluster formation (Sharp et al., 2009). Our data corroborates this observation, as the majority of tissue samples from elderly patients demonstrated pronounced degenerative changes in the cell cluster microstructure.

Like all tissues in the human body, the intervertebral disc is subject to natural aging processes that are associated with microstructural changes. Although histological studies using light microscopy have been established in medical diagnostics, the present study demonstrates that SEM histological examinations enable more detailed analysis thanks to two primary factors. On one hand, higher magnification allows greater analysis of cell morphology such as the cell density, cell sizes, and extracellular matrix which can be quantified using digital image analysis. The other major advantage relates to the preparation method. Histological slices prepared via paraffin wax embedding can only be used for electron microscopy using expensive reburial that is associated with losses in structural preservation (Hübner, 1970). Choosing a plastic-based embedding system allows for the preparation of hard tissue as well as electron microscopy studies. Tissue sample crosssections can be investigated either directly from the plastic block or from thin slices created via the cutting-grinding technique (Donath, 1985; Willbold and Witte, 2010). For both methods, the tissue sample is processed by applicable sawing and grinding techniques; the fixation of thin sections on glass slides, which is necessary for common histology, can be bypassed. This is primarily an important consideration for studies of tissue matrix damage, as damage caused from preparation methods may lead to erroneous results.

For both methods it is equally problematic that the examined samples cannot reproduce an exact image of the tissue state. It is known that the proteoglycans contained in the NP swell when exposed to water (Chung et al., 2003; Zhang et al., 2011). Even if the water content of epidural adipose tissue is small (Schirmer, 1921), the tissue comes into contact with blood, and therefore water, from the surgical corridor during the operation. As a direct fixation inside the spinal canal is not possible, all histological preparations form a temporally displaced state.

\section{Conclusions}

In this work, sequestered IVD tissue was successfully characterized using histology, light microscopy, and SEM to evaluate parameters of interest for IVD degeneration such as delamination of the collagenous matrix, cell density, cell size, and ECM thickness. The techniques used allowed for high resolution, quantitative assessment of morphological features that may be indicative of the degenerative process, and enabled evaluations of statistically significant correlations to clinical patient data such as sex and age. Such studies can be applied to other tissues; this methodology provides a valuable addition to the existing portfolio of available techniques in medical research for investigating micromorphological changes of tissue samples. Due to the limited sequestrum volumes of $1-2 \mathrm{~cm}^{3}$, further work evaluating larger samples, such as in a cadaver study, would prove beneficial for shedding additional light on the complex incidence of IVD degeneration.

\section{Acknowledgements}

The authors are grateful to F. Benjamin, W. Petzold and I. Auge from the Fraunhofer IMWS for technical assistance as well as to the neurosurgical staff of the BG Klinikum Bergmannstrost Halle $\mathrm{gGmbH}$ for cooperation. Our special thanks to all patients who agree to use their tissue for research purposes. This work was supported by the German Federal Ministry of Education and Research (BMBF, PtJ-Bio, 0315883), the European Union, European fund for regional development (Sachsen-Anhalt, EFRE, FuE 1104/00062) and the Whitaker Biomedical Engineering Research Fellowship.

\section{References}

Adams, P.J., Roughley, M.A., 2006. What is intervertebral disc degeneration, and what causes it? Spine 31, 2151-2161.

Antoniou, J., Steffen, T., Nelson, F., Winterbottom, N., Hollander, A.P., Poole, R.A. Aebi, M., Alini, M., 1996. The human lumbar intervertebral disc - Evidence for changes in the biosynthesis and denaturation of the extracellular matrix with growth, maturation, ageing, and degeneration. J. Clin. Invest. 98, 996-1003.

Buckwalter, J.A., 1995. Aging and degeneration of the human intervertebral disc. Spine 20, 1307-1314.

Carlson, R.L., Kardomateas, G., Craig, J.I., 2012. Mechanics of Failure Mechanisms in Structures. Springer, Netherlands.

Chung, S.A., Khan, S.N., Diwan, A.D., 2003. The molecular basis of intervertebral disk degeneration. Orthop. Clin. North Am. 34, 209-219.

Ciapetti, G., Granchi, D., Devescovi, V., Leonardi, E., Greggi, T., Di Silvestre, M., Baldini, N., 2012. Ex vivo observation of human intervertebral disc tissue and cells isolated from degenerated intervertebral discs. Eur. Spine J. 21, 10-19.

Colombier, P., Clouet, J., Hamel, O., Lescaudron, L., Guicheux, J., 2014. The lumbar intervertebral disc: from embryonic development to degeneration. Joint Bone Spine 81, 125-129.

Ding, F., Shao, Z., Xiong, L., 2013. Cell death in intervertebral disc degeneration. Apoptosis 18, 777-785.

Donath, K., 1985. The diagnostic value of the new method for the study of undecalcified bones and teeth with attached soft tissue, (SÃ age-Schliff, (Sawing and grinding) technique). Pathol.-Res. Pract. 179, 631-633.

Duance, V.C., Crean, J.K.G., Sims, T.J., Avery, N., Smith, S., Menage, J., Eisenstein, S.M., Roberts, S., 1998. Changes in collagen cross-linking in degenerative disc disease and scoliosis. Spine 23, 2545-2551.

Ford, J.L., Jones, P., Downes, S., 2002. Cellularity of human annulus tissue: an investigation into the cellularity of tissue of different pathologies. Histopathology 41, 531-537.

Friedmann, A., Cismak, A., Tautorat, C., Koester, P.J., Baumann, W., Held, J., Gaspar, J., Ruther, P., Paul, O., Heilmann, A., 2012. FIB preparation and SEM investigations for three-dimensional analysis of cell cultures on microneedle arrays. Scanning 34, 221-229.

Gruber, H.E., Hanley Jr., E.N., 1998. Analysis of aging and degeneration of the human intervertebral disc: comparison of surgical specimens with normal controls. Spine 23, 751-757.

Gruber, H.E., Ingram, J.A., Norton, H.J., Hanley, E.N.J., 2007. Senescence in cells of the aging and degenerating intervertebral disc: immunolocalization of senescence-associated $\hat{I}^{2}$-Galactosidase in human and sand rat discs. Spine 32, $321-327$. 
Hübner, G., 1970. Fine structure of formalin-fixed biopsy- and autopsy-specimens after paraffin-embedding. Virchows Archiv A 351, 155-167.

Hadjipavlou, A.G., Tzermiadianos, M.N., Bogduk, N., Zindrick, M.R., 2008. The pathophysiology of disc degeneration. J. Bone Joint Surg.-Br. 90B, 1261-1270.

Hristova, G.I., Jarzem, P., Ouellet, J.A., Roughley, P.J., Epure, L.M., Antoniou, J., Mwale, F., 2011. Calcification in human intervertebral disc degeneration and scoliosis. J. Orthop. Res. 29, 1888-1895.

Johnson, W.E., Eisenstein, S.M., Roberts, S., 2001. Cell cluster formation in degeneratee lumbar intervertebral discs is associated with increased disc cell proliferation. Connect. Tissue Res. 42, 197-207.

Kepler, C.K., Ponnappan, R.K., Tannoury, C.A., Risbud, M.V., Anderson, D.G., 2013. The molecular basis of intervertebral disc degeneration. Spine J. 13, 318-330.

Kobayashi, S., Meir, A., Kokubo, Y., Uchida, K., Takeno, K., Miyazaki, T., Yayama, T. Kubota, M., Nomura, E., Mwaka, E., Baba, H., 2009. Ultrastructural analysis on lumbar disc herniation using surgical specimens role of neovascularization and macrophages in hernias. Spine 34, 655-662.

Le Maitre, C.L., Freemont, A.J., Hoyland, J.A., 2007. Accelerated cellular senescence in degenerate intervertebral discs: a possible role in the pathogenesis of intervertebral disc degeneration. Arthritis Res. Ther. 9, 45-57.

Lee, R.S., Kayser, M.V., Ali, S.Y., 2006. Calcium phosphate microcrystal deposition in the human intervertebral disc. J. Anat. 208, 13-19.

Majeed, S.A., Seshadrinath, N.A.K., Binoy, K.R., Raji, L., 2016. Lumbar disc herniation: is there an association between histological and magnetic resonance imaging findings. Indian J. Orthop. 50, 234-241.

Mulisch, M., Welsch, U. (Eds.), 2010. Romeis - Mikroskopische Technik. Springer Berlin Heidelberg.

Pai, R.R., D’sa, B., Raghuveer, C.V., Kamath, A., 1999. Neovascularization of nucleus pulposus-a diagnostic feature of intervertebral disc prolapse. Spine 24 739-741.

Pfirrmann, N., Metzdorf, C.W., Zanetti, A., Hodler, M., Boos, J., 2001. Magnetic resonance classification of lumbar intervertebral disc degeneration. Spine 26, 1873-1878.

Postacchini, F., Cinotti, G., 1999. Disc Herniation Associated to Other Conditions. In: LumbarDiscHerniation. Springer Vienna, pp. 539-556.

Raj, P.P., 2008. Intervertebral Disc: Anatomy-Physiology-Pathophysiology-Treatment. Pain Pract. 8, 18-44.

Roberts, S., Evans, E.H., Kletsas, D., Jaffray, D.C., Eisenstein, S.M., 2006a. Senescence in human intervertebral discs. Eur. Spine J. 15, S312-S316.

Roberts, S., Evans, H., Trivedi, J., Menage, J., 2006b. Histology and pathology of the human intervertebral disc. J. Bone Joint Surg. 88, 10-14

Schirmer, O., 1921. Über die Zusammensetzung des Fettgewebes unter verschiedenen physiologischen und pathologischen Bedingungen. Archiv für Experimentelle Pathologie und Pharmakologie 89, 263-279.

Sharp, C.A., Roberts, S., Evans, H., Brown, S.J., 2009. Disc cell clusters in pathological human intervertebral discs are associated with increased stress protein immunostaining. Eur. Spine J. 18, 1587-1594.

Siemionow, K., An, H., Masuda, K., Andersson, G., Cs-Szabo, G., 2011. The effects of age, sex, ethnicity, and spinal level on the rate of intervertebral disc degeneration a review of 1712 intervertebral discs. Spine 36, 1333-1339.
Singh, K., Masuda, K., Thonar, E.J.-M.A., An, H.S., Cs-Szabo, G., 2009. Age-related changes in the extracellular matrix of nucleus pulposus and anulus fibrosus of human intervertebral disc. Spine 34, 10-16.

Smith, L., Fazzalari, N., 2009. The elastic fibre network of the human lumbar anulus fibrosus: architecture, mechanical function and potential role in the progression of intervertebral disc degeneration. Eur. Spine J. 18, 439-448.

Tomaszewski, K.A., Walocha, J.A., Mizia, E., Gladysz, T., Glowacki, R., Tomaszewska, R., 2015. Age- and degeneration-related variations in cell density and glycosaminoglycan content in the human cervical intervertebral disc and its endplates. Pol. J. Pathol. 66, 296-309.

Trout, J.J., Buckwalter, J.A., Moore, K.C., Landas, S.K., 1982. Ultrastructureofthe human intervertebral disc: I. Changes in notochordal cells with age. Tissue Cell 14, 359-369.

Urban, J.P.G., Roberts, S., Ralphs, J.R., 2000. The nucleus of the intervertebral disc from development to degeneration. Am. Zool. 40, 53-61.

Vergroesen, P.-P.A., Kingma, I., Emanuel, K.S., Hoogendoorn, R.J.W., Welting, T.J., Royen, B.J., Dieen, van, van, J.H., Smit, T.H., 2015. Mechanics and biology in intervertebral disc degeneration: a vicious circle. Osteoarthr. Cartil. 23 , 1057-1070.

Vernon-Roberts, B., Moore, R.J., Fraser, R.D., 2007. The natural history of age-related disc degeneration: the pathology and sequelae of tears. Spine 32, 2797-2804

Whatley, B.R., Wen, X., 2012. Intervertebral disc (IVD): Structure, degeneration, repair and regeneration. Mater. Sci. Eng.: C 32, 61-77.

Willbold, E., Witte, F., 2010. Histology and research at the hard tissue implant interface using Technovit 9100 New embedding technique. Acta Biomater. 6 , 4447-4455.

Woods, B.I., Sowa, G., Vo, N., Kang, J.D.W., 2010. A Change in Strategy: The use of regenerative medicine and tissue engineering to augment the course of intervertebral disc degeneration. Oper. Tech. Orthop. 20, 144-153.

Yerramalli, C.S., Chou, A.I., Miller, G.J., Nicoll, S.B., Chin, K.R., Elliott, D.M., 2007. The effect of nucleus pulposus crosslinking and glycosaminoglycan degradation on disc mechanical function. Biomech. Model. Mechanobiol. 6, 13-20.

Zhang, Y., Chee, A., Thonar, E.J., An, H.S., 2011. Intervertebral disk repair by protein, gene, or cell injection: a framework for rehabilitation-focused biologics in the spine. PM \& R 3, S88-S94.

Zhao, C.-Q., Wang, L.-M., Jiang, L.-S., Dai, L.-Y., 2007. The cell biology of intervertebral disc aging and degeneration. Ageing Res. Rev. 6, 247-261.

\section{Further reading}

Aescht E., Büchl-Zimmermann S., Burmester A., DänhardtPfeiffer S., Desel C., Hamers C., Jach G., Kässens M., Makovitzky J., Mulisch M., Nixdorf-Bergweiler B., Pütz D., Riedelsheimer B., Boom van den F., Wegerhoff R., Welsch U., 2010. Romeis-Mikroskopische, Springer Spektrum. 